\title{
EL DERECHO DEL AUTOR ASALARIADO EN ARGENTINA
}

\author{
AUGUSTO H. L. ARDUINO \\ SILVANA S. ORTIZ \\ FACULTAD DE DERECHO Y CIENCIAS SOCIALES Y POLÍTICAS \\ UNIVERSIDAD NACIONAL DEL NORDESTE
}

ARGENTINA

"El trabajo es un título natural para la propiedad del fruto del mismo, y la legislación que no respete ese principio es intrínsecamente injusta". Jaime Luciano Balmes 


\begin{tabular}{c}
\hline $110<\quad$ AUGUSTO H. L. ARDUINO - SILVANA S. ORTIZ \\
EL DERECHO DEL AUTOR ASALARIADO EN ARGENTINA \\
Pags. $108-123$
\end{tabular}

Recibido: 10/03/2014

Aceptado: 19/05/2014

\title{
RESUMEN
}

\begin{abstract}
l autor contratado bajo relación de dependencia laboral en la Argentina no se encuentra regulado en la legislación sobre derecho de autor. La ley número 11723 no contempla la figura, y la reforma de la ley número 25.036 en su art. 2 solo hace referencia a los programas de computación realizados en virtud de un contrato laboral. No obstante, la ley de patentes número 24481 modificada por ley número 24572, ha regulado la cuestión de los derechos de explotación de patentes de invención, mediando relación contractual. Asimismo se ha regulado en ley número 20.744 lo relativo a las invenciones del trabajador. En la ley de patentes de invención se regula la situación del inventor contratado o asalariado. El derecho laboral y la propiedad intelectual en general, y en particular el derecho de autor son de naturaleza diversa y tienen regulaciones específicas con principios jurídicos propios. Por ello, se abordará cada temática desde su generalidad a fin de arribar al tratamiento del problema planteado.
\end{abstract}

Palabras claves: propiedad intelectual, relación laboral, derecho moral, derecho de autor.

\begin{abstract}
:
The author contracted under a labor relationship in Argentina is not regulated by copyright law. Law number 11723 does not provide the figure, and the reform of Law No. 25.036 in art. 2 alone refer to computer programs made under an employment contract. Nevertheless, patent law number 24481 as amended by Law No. 24572, has regulated the issue of rights to use patents, mediating contractual relationship. Also it has been regulated in the Labor Contract Law regarding employee inventor. In the law of patents the employee inventor is regulated. Labour law and intellectual property in general, and in particular copyright, are diverse in nature, and they have specific regulations with own legal principles. Therefore, each subject will be approached from its generality to arrive at the treatment of the problem.
\end{abstract}

Keywords: intellectual property, labour relationship, moral rights, copyright.

\section{INTRODUCCIÓN:}

El autor contratado bajo relación de dependencia laboral en la Argentina no se encuentra contemplado en la legislación. La ley número 11723 Régimen de Propiedad Intelectual, no observa la figura, y la reforma introducida por la ley número 25.036 en su art. 2 solo hace referencia a los programas de computación realizados en virtud de un contrato laboral.

Cabe aclarar que la propiedad intelectual se divide en derecho industrial y derecho de autor. Está comprendida dentro de la primera categoría la ley de patentes de invención número 24481 modificada por ley número 24572, que ha regulado la cuestión de los derechos de ex- 
plotación de patentes de invención, mediando relación contractual. Asimismo se ha regulado en ley número 20744, Ley de Contrato de Trabajo, lo relativo a las invenciones del trabajador. En el régimen jurídico argentino se regula la situación del inventor contratado o asalariado pero no así la situación del autor asalariado destacando que estas categorías de derechos de propiedad intelectual tienen fundamentación distinta en cuanto a su protección.

El derecho laboral y la propiedad intelectual en general, y en particular el derecho de autor son de naturaleza diversa y tienen regulaciones específicas con principios jurídicos propios.

En el presente trabajo se abordará cada temática desde su generalidad a fin de arribar al tratamiento del problema planteado desde lo teórico primeramente, para finalmente abordar la cuestión desde la práctica jurídica evidenciándose así la necesidad de revisar las teorías existentes y brindar un aporte al problema.

\section{PROPIEDAD INTELECTUAL}

La protección de la propiedad intelectual se divide en dos categorías: la propiedad industrial, que incluye las invenciones, patentes, marcas, dibujos y modelos industriales e indicaciones geográficas de procedencia; y el derecho de autor, que abarca las obras literarias y artísticas, tales como las novelas, los poemas y las obras de teatro, las películas, las obras musicales, las obras de arte, tales como los dibujos, pinturas, fotografías y esculturas, y los diseños arquitectónicos (OMPI., www.wipo.int, 2013).

Actualmente cuando hablamos de derechos intelectuales, no sólo abordamos la temática de los derechos de autor, legislados por la Ley de Propiedad Intelectual $\mathrm{N}^{\circ} 11723^{1}$, sino también de los que tienen por objeto los inventos, las marcas y los diseños y los modelos industriales y de utilidad (ARDUINO Augusto H.L., AZEVES Ángel Héctor, 2007).

La propiedad intelectual se integra por una serie de facultades susceptibles de ser agrupadas, por un lado en el derecho moral de autor, y por el otro en los derechos de explotación patrimonial o dineraria. Junto a ellos es necesario citar la existencia de los denominados derechos conexos o afines. Los derechos morales se caracterizan por las notas de irrenunciabilidad e inalienabilidad y por ser indisponibles, al ser nulo todo pacto o contrato que suponga transmisión o renuncia de los mismos. Pueden ser definidos como el conjunto de derechos inherentes a la persona del autor y de hecho, la corriente dominante dentro de la doctrina considera que se trata de unos derechos de la personalidad o, al menos participan de muchos de los caracteres tradicionalmente asignados a éstos. Además los derechos morales se caracterizan por su perpetuidad (GOMEZ, 2000, págs. 36-38).

\footnotetext{
${ }^{1}$ Ley de Propiedad Intelectual N 11723 BO 30 de septiembre de 1933.
} 
En los últimos años la propiedad intelectual ha adquirido gran relevancia por su valoración en el mercado atento al incremento de su compensación económica. Esto se debe en mayor medida a que la propiedad intelectual confiere al autor de una obra derechos monopólicos lo que supone grandes inversiones empresariales para la explotación de las obras intelectuales.

\section{DERECHO DE AUTOR}

En el presente apartado nos ocuparemos del alcance del derecho de autor, su naturaleza jurídica y sus principios.

El derecho de autor se aplica a las creaciones artísticas como los poemas, las novelas, las obras musicales, las pinturas y las obras cinematográficas. En inglés, a diferencia de los demás idiomas europeos, el derecho de autor se conoce con el nombre de "copyright". El término copyright tiene que ver con actos fundamentales que, en lo que respecta a creaciones literarias y artísticas, sólo pueden ser efectuados por el autor o con su autorización. La expresión, derecho de autor, nos remite a la persona creadora de la obra artística, a su autor, subrayando así el hecho que se reconoce en la mayor parte de las leyes, en el sentido de que el autor goza de derechos específicos en relación con su creación, como el derecho a impedir la reproducción deformada de la misma, prerrogativa que sólo a él le pertenece, mientras que existen otros derechos, como el derecho a efectuar copias, del que pueden gozar terceros, por ejemplo, todo editor que haya obtenido una licencia del autor con ese fin (OMPI., www.wipo.int, 2013, 20/11/2013).

La ley 11.723 - Propiedad intelectual en su artículo $1^{\circ}$ dispone “A los efectos de la presente ley, las obras científicas, literarias y artísticas, comprenden los escritos de toda naturaleza y extensión; las obras dramáticas, composiciones musicales, dramático-musicales; las cinematográficas y pantomímicas; las obras de dibujos, pintura, escultura, arquitectura; modelos y obras de arte o ciencia aplicadas al comercio o a la industria; los impresos, planos y mapas; los plásticos, fotografías, grabados y discos fonográficos, en fin: toda producción científica, literaria, artística o didáctica sea cual fuere el procedimiento de reproducción" (Argentina, Ley 11.723, Ley Modificatoria Ley No 25.036 B. O 11/11/1998).

\subsection{Naturaleza Jurídica del Derecho de autor.}

Conforme lo señalara Emery la jurisprudencia argentina, en forma uniforme y pacífica, ha reafirmado la naturaleza jurídica adoptada por el legislador para la protección de los derechos intelectuales de los autores y otros titulares, al expresar que en el ordenamiento positivo nacional el derecho intelectual está asimilado al derecho real de dominio, de modo que el autor goza sobre su obra de todos los derechos del propietario, entre los cuales se encuentran los de publicarla, exponerla en público y enajenarla (art. $2^{\circ}$ Ley 11 723), por la vía que estime más 
apropiada. En caso de enajenación, su adquirente puede publicar la obra, pero respetando los derechos del autor a que se conozca su autoría (art. 52, Ley 11723) (EMERY M. Á., 2009, pág. 9). Reconociendo así, aunque incipientemente, el derecho moral de autor.

Los artículos 51 y 52 de la Ley 11723 reconocen el derecho moral de autor consagrado por la legislación argentina. Por su parte el artículo 51 impide al cesionario la posibilidad de alterar el título, forma o contenido de la obra, y, asimismo el artículo 52 reafirma el derecho a exigir la fidelidad del texto y del título en las reproducciones de ella.

En el caso "Artlt Cristophersen" se dijo que el derecho intelectual o de autor tiene dos aspectos: el moral y el pecuniario (económico o patrimonial). El primero es un derecho personalísimo y está fuera del comercio, no discutiéndose que pertenece exclusivamente al creador de la obra y que no entra en la sociedad conyugal. El segundo, en cambio, es un bien que, como "susceptible de valor", entra dentro de la categoría de "objetos inmateriales" que comprende el art. 2312 de nuestro Código Civil (ARDUINO \& AZEVES, 2010, pág. 1141).

Por lo tanto, en cuanto a su naturaleza jurídica, hay teorías que lo consideran un derecho meramente moral (teoría monista) o teorías que consideran que es un derecho moral y patrimonial (teoría dualista). La teoría monista considera que el derecho de autor es un derecho de la personalidad, y, en este caso, su principal característica sería su intransmisibilidad por actos inter vivos, lo cual podría perjudicar el normal tráfico de mercancías. El dualismo representó, desde un punto de vista jurisprudencial y doctrinal, un avance en la lucha por el reconocimiento del derecho de autor en su máxima amplitud; sin embargo, la necesidad de una mayor precisión científica y dogmática hizo que la doctrina se volviera una vez más hacia el monismo reformulado que ha tenido en cuenta toda la evolución del denominado derecho moral, en cuanto reflejo de la dignidad de la persona humana (ESPÍN ALBA, 1994, pág. 7).

Aunque existen varias corrientes dentro de este nuevo monismo, el rasgo esencial de sus principales teorías es la prevalencia de los derechos morales sobre el aspecto patrimonial de derecho de autor. La crítica referida a la intransmisibilidad que siempre ha sido dirigida a las concepciones unitarias personalistas tradicionales, vuelve a ser dirigida al nuevo monismo. De allí que la delimitación de la naturaleza jurídica del derecho de autor pueda traer inconvenientes prácticos en lo que refiere a la posibilidad de la transmisión de las facultades inherentes al mismo.

En nuestro sistema jurídico de origen continental, se encuentra arraigada la concepción europea del derecho moral de autor, diferenciándose con los derechos a las patentes de invención propios del derecho industrial que se protege no tanto a la creación del intelecto como a la inversión económica.

En cuanto a la delimitación del derecho moral de autor, la legislación española delimita su contenido y características en el artículo 14 del Real Decreto Español 1/1996, de 12 de abril, por el que se aprueba el Texto Refundido de la Ley de Propiedad Intelectual, regularizando, aclarando y armonizando las disposiciones legales vigentes sobre la materia, donde se establece que: "Corresponden al autor los siguientes derechos irrenunciables e inalienables: 
1. Decidir si su obra ha de ser divulgada y en qué forma.

2. Determinar si tal divulgación ha de hacerse con su nombre, bajo seudónimo o signo, o anónimamente.

3. Exigir el reconocimiento de su condición de autor de la obra.

4. Exigir el respeto a la integridad de la obra e impedir cualquier deformación, modificación, alteración o atentado contra ella que suponga perjuicio a sus legítimos intereses o menoscabo a su reputación.

5. Modificar la obra respetando los derechos adquiridos por terceros y las exigencias de protección de bienes de interés cultural.

6. Retirar la obra del comercio, por cambio de sus convicciones intelectuales o morales, previa indemnización de daños y perjuicios a los titulares de derechos de explotación.

$\mathrm{Si}$, posteriormente, el autor decide reemprender la explotación de su obra deberá ofrecer preferentemente los correspondientes derechos al anterior titular de los mismos y en condiciones razonablemente similares a las originarias.

7. Acceder al ejemplar único o raro de la obra, cuando se halle en poder de otro, a fin de ejercitar el derecho de divulgación o cualquier otro que le corresponda.

Este derecho no permitirá exigir el desplazamiento de la obra y el acceso a la misma se llevará a efecto en el lugar y forma que ocasionen menos incomodidades al poseedor, al que se indemnizará, en su caso, por los daños y perjuicios que se le irroguen” (Real Decreto Español Legislativo 1/1996, de 12 de abril, por el que se aprueba el Texto Refundido de la Ley de Propiedad Intelectual, regularizando, aclarando y armonizando las disposiciones legales vigentes sobre la materia).

\section{2. Principios de la Propiedad intelectual.}

Siguiendo a Carranza Torres (CARRANZA TORRES, 2011 Cita Online: AR/DOC/6055/2011) los principios básicos son los siguientes: a) el autor es propietario de su obra desde el momento mismo de su creación, sin necesidad de registro o cumplimiento de alguna otra formalidad. Está expresamente consagrado por el Convenio de Berna, del que es parte nuestro país; b) los derechos patrimoniales no están sujetos a lo que se conoce como numerus clausus, sino que, al contrario, son tantos como formas de utilización de la obra sean factibles; c) un principio relacionado al anterior es el de la independencia de los derechos patrimoniales. Cada una de esas formas factibles de utilización o explotación de la obra intelectual es independiente de las demás; d) por otro lado entre sus facultades exclusivas están las de autorizar a terceros a usar o explotar su obra o cederles sus derechos de propiedad. En este sentido, la ley argentina dispone que "el autor o sus derechohabientes pueden enajenar o ceder total o parcialmente su obra"; e) para los terceros, todo lo que no está expresamente permitido por el autor o titular de los derechos, está prohibido. Es decir, sin autorización del autor o titular de los derechos cualquier uso o explotación de la obra por parte de terceros es ilícito, porque viola su derecho de propiedad; f) asimismo el autor puede disponer de 
su obra, en este sentido, el autor o titular de los derechos puede decidir libremente explotar la obra por sí mismo, ceder su explotación a otro, limitar esa cesión en el tiempo o en el espacio, enajenar su derecho de propiedad o no explotarla; g) debido a que el autor tiene todas las facultades de explotación, que éstas son independientes entre sí y que puede disponer de ellas a su antojo, no sólo está facultado para autorizar a terceros determinados usos o explotación, sino que se use o explote con tal o cual destino; h) por otro lado, los contratos en los que el autor o titular cede, transmite o autoriza el uso o explotación de su obra deben ser interpretados restrictivamente y, en ese espíritu, en caso de duda acerca de si un determinado uso o explotación de la obra ha sido o no autorizado en el caso concreto, el juez deberá inclinarse a favor del autor o titular; i) en relación a la carga de la prueba, en caso de disputa acerca del alcance de los derechos autorizados o cedidos y ante la ausencia de autorización expresa, es el tercero usuario o adquirente de la obra el que deberá probar que tiene los derechos que afirma tener.

\section{Derecho del Trabajo.}

Debido a la especialidad con que se trata en el derecho argentino la relación de dependencia existente entre el asalariado y la empresa contratante, es menester abordar primeramente el tema desde las notas propias que la relación de dependencia le da a éste tipo de contratación.

\subsection{La relación de dependencia:}

El concepto de dependencia laboral ha sido siempre motivo de cuestionamientos, aunque actualmente se ve acentuada ésta tendencia por las nuevas formas de relación laboral que surgen en razón de la cambiante realidad socioeconómica.

Actualmente para la determinación de la relación de dependencia se utiliza habitualmente la idea de la subordinación funcional, bajo el aspecto de la subordinación jurídica. La justicia ha recurrido así a la técnica del haz de índices, que consiste en fundar la calificación del contrato sobre un conjunto de signos objetivos de subordinación, sin considerar ninguno de estos signos como necesario y suficiente. Figuran es esta lista de índices, por ejemplo: la imposición de los tiempos y lugares de trabajo, el respeto de los procedimientos, de los programas o de los sectores geográficos, la obligación de rendir cuentas, el modo de remuneración, el suministro de los medios de trabajo, la existencia de un compromiso de exclusividad o de una cláusula de no competencia, el comportamiento "patronal" de quien da órdenes (SUPIOT, 2008, pág. 73).

La utilización judicial de ésta técnica establecida en base a la jurisprudencia, puede acarrear decisiones insatisfactorias puesto que nuestro ordenamiento laboral no atiende, salvo excepcionalmente, situaciones que podríamos llamar de dependencia relativa o diluida. Con ésta técnica puede que se beneficie totalmente al sujeto que quiere hacer valer su pretensión, o que quede, sin escalas, totalmente excluido del sistema tutelar del derecho laboral (ACKERMAN, 2008, pág. 159). No obstante, como se infiere de la letra de la Ley de Contrato de Trabajo 20744 en sus arts. 4, 21, 22, 27 el ordenamiento positivo decididamente concede relevancia al perfil jurídico de la subordinación caracterizado fundamentalmente por la efectiva o potencial 
determinación heterónoma de la prestación de servicios y el ejercicio del poder disciplinario (ACKERMAN, 2008, pág. 164).

\subsection{Los principios del derecho laboral. Principio protectorio:}

Conforme la doctrina mayoritaria la existencia de relación de dependencia supone la aplicación del derecho laboral, derecho de orden público que conlleva una serie de principios que rigen en razón de su especificidad: a) principio protectorio b) principio de buena fe; c) principio de equidad; d) principio de justicia social; e) principio de razonabilidad; f) principio de igualdad de trato; g) principio de primacía de la realidad.

En razón de su importancia es necesario explayar, aunque brevemente, el principio protectorio. El cual, como señala Ackerman es una directriz política o una preferencia axiológica que reclama que en las relaciones laborales se otorgue una tutela o amparo preferente a las personas que trabajan (ACKERMAN, 2008, pág. 319).

Como lo sostiene la doctrina, en general, el fundamento del principio protectorio radica en la desigualdad de las partes vinculadas por un contrato de trabajo, y a partir de la lógica de corregir ésta desigualdad con la creación de otras desigualdades.

"El Derecho del Trabajo puede ser visto, así, como un sistema normativo - inicialmente de fuente estatal y luego completado con los productos de la autonomía colectiva - que reconoce tanto la falta de libertad de quien es contratado - carencia que, a su vez, es consecuencia de su necesidad económica - como la resignación de la libertad que supone la sumisión a los poderes jerárquicos del empleador como condición ineludible para acceder a un sustento. Y, a partir de tales reconocimientos, el Derecho del Trabajo despliega un conjunto de reglas y diseña medios técnicos para poner límites tanto al ejercicio de la posición de supremacía del empleador como a la entrega de las libertades por el trabajador" (ACKERMAN, 2008, Pág. 319 y 320).

Este principio no sólo impregna todo el ordenamiento jurídico laboral, sino también su interpretación y aplicación al caso concreto, como así también a la valoración de la prueba. Tal es así que se ha establecido por la doctrina una serie de reglas de aplicación que son: a) "la regla de la norma más favorable al trabajador"; b) "la regla de la interpretación más favorable al trabajador" (in dubio pro operario); c) "la regla de la condición de trabajo más beneficiosa"; d) "la regla de la irrenuciabilidad".

"Este principio protectorio, junto con el principio de la primacía de la realidad, coadyuva a la determinación de la subordinación jurídica, lo que permite, desde una interpretación amplia de la misma, capturar las fugas fraudulentas del contrato de trabajo" (AMEGLIO, 2009, pág. 232).

\section{Derecho Laboral y Derecho de Autor.}

Hecha estas consideraciones previas en torno al Derecho del Trabajo, es menester pun- 
tualizar en el supuesto de la existencia de una relación laboral entre el creador de una obra y su empleador.

No obstante las particularidades que reviste el Derecho Laboral, cabe resaltar la opinión de Emery, quien considera que, "si bien la Ley 11723 no legislaba sobre el tema; sin embargo, por la remisión que hace el art. 12 a los principios generales derecho, son de aplicación el art. 1623 y ss. del Cód. Civil, referentes a la locación de servicios, de lo que resulta la propiedad intelectual originaria del empresario que las encarga cuando se trata de obras literarias artísticas "colectivas" realizada por aportantes anónimos (conf. Arts. $8^{\circ}$ y 16)” (EMERY M. Á., 2009, pág. 55).

El mencionado autor continua diciendo que por esta remisión y por aplicación analógica del art. 29 de la Ley 11723 y del art. 82 de la ley de contrato de trabajo (reglamentado por el art. 10 de la ley 24481, t.o. decr. 260/96) permitía concluir legítimamente que, al ser el empleador quién dirige, costea y produce la obra, a él corresponden los derechos patrimoniales de lo producido en el tiempo y con ocasión del contrato de empleo. Es decir que le pertenecen los derechos para explotar la obra pero los derechos morales y aquellos que excedan del contenido del contrato de trabajo pertenecen al autor (EMERY M. Á., 2009, pág. 10).

Éste fue, oportunamente, el posicionamiento adoptado también por la jurisprudencia argentina al reconocer que la paternidad de la obra intelectual corresponde a su creador, pero como propiedad pertenece jurídicamente al empleador (1963).

Así también la reciente ley 25.036 en su art. 2 que reforma el art. 4 de la ley 11723 de Propiedad Intelectual en su inc. $d$ al referirse a los programas de computación establece que "Son titulares del derecho de propiedad intelectual: (...) d) Las personas físicas o jurídicas cuyos dependientes contratados para elaborar un programa de computación hubiesen producido un programa de computación en el desempeño de sus funciones laborales, salvo estipulación en contrario" (Argentina, Ley 11.723, Régimen de Propiedad Intelectual).

No obstante, la Ley 11723 no regula específicamente qué aspectos constituyen el derecho moral de autor, ni que comprende el derecho a la explotación por parte del empleador. Asimismo tampoco regula el derecho a la divulgación y la posibilidad del autor a retractarse de la publicación de su obra mediando contrato de empleo, y menos aún hasta cuándo puede hacer uso de la retractación y si debe pagar indemnización al empresario contratante que detenta la explotación de la misma. En estos casos el autor se compromete a entrega la obra o a ceder derechos de explotación sobre ella sin haberla creado, por ello es muy difícil apreciar el alcance de los derechos del autor asalariado y del empresario contratante (PEREZ DE ONTIVEROS BAQUERO Carmen, 1993, pág. 274).

Por su parte, la ley de patentes de invención la ley 24481 modificada por ley 24572, ha regulado la cuestión de los derechos de explotación de patentes de invención, mediando relación contractual. Asimismo se han regulado en la Ley de Contrato de Trabajo lo relativo a las invenciones del trabajador. En la ley de patentes de invención se regula la situación del inventor contratado o asalariado. En este último caso no se contempla la posibilidad de que el trabajador se oponga a la explotación de su invento pudiendo indemnizar al empleador. El 
invento es de propiedad del empleador ab initio y el trabajador solo tiene la facultad de ser reconocido como el inventor de la obra.

Este vínculo jurídico provoca, de tal manera, la transferencia originaria de la propiedad de los resultados del trabajo, a favor del acreedor de la prestación. Los productos transformados por el trabajo pertenecen ab initio al titular de la organización empresarial, por cuanto el contrato de trabajo produce el efecto de transferir el derecho al producto del trabajo - siempre que consista la creación de una cosa nueva - al empleador. Una excepción a este principio la constituyen los derechos inmateriales (como los de autor o inventor) que con relación al producto del trabajo podrían nacer y respecto de los cuales es discutible la cuestión de saber a quién pertenecen. En el caso de las invenciones es el más frecuente y al mismo tiempo el más difícil de regular. En nombre de quién ha de extenderse la patente respectiva o quién debe ser nombrado en ella como autor, es decir, a quién corresponde la propiedad (inmaterial) o por lo menos el "derecho moral" sobre la invención.

En cuanto a las invenciones contractuales, profesionales o de servicio: Los inventos llevados a cabo por el trabajador durante la relación laboral cuyo objeto es la realización de actividades inventivas pertenecen al empleador (art. 10 inc. a. del texto ordenado).

El derecho a obtener la patente pertenece al empleador: En los casos en que el aporte personal del trabajador a la invención y la importancia de ésta para la empresa y el empleador excediese de manera evidente el contenido explícito o implícito del contrato, la nueva ley reconoce al trabajador el derecho, no previsto en la Ley de Contrato de Trabajo, en adelante LCT, al cobro de una remuneración.

En lo que refiere al derecho de autor, éste puede crear su obra espontáneamente sin mediar obligación contractual, o ser contratado para ello y por lo tanto estar ligado a una tercera persona en virtud de éste contrato. Puede suceder inclusive que se establezcan condiciones determinadas para la creación de la obra, o que el autor pueda realizarla con entera libertad. Pero en caso de mediar una contratación no se ha dispuesto por la ley de qué manera se compatibilizarán los derechos del autor asalariado sobre la obra y los derechos de la empresa contratante.

En el derecho argentino no existe una regulación que delimite el ejercicio del derecho por parte del autor que ha sido contratado para la creación de una obra. Así como tampoco se encuentra regulado el derecho a la divulgación de su obra, simplemente lo reconoce al regular el derecho a la publicación.

La legislación española sobre propiedad intelectual distingue en su artículo 4, ", se entiende por divulgación de una obra toda expresión de la misma que, con el consentimiento del autor, la haga accesible por primera vez al público en cualquier forma; y por publicación, la divulgación que se realice mediante la puesta a disposición del público de un número de ejemplares de la obra que satisfaga razonablemente sus necesidades estimadas de acuerdo con la naturaleza y finalidad de la misma” (Real Decreto Legislativo Español 1/1996 12 de abril de 1996, por el que 
se aprueba el Texto Refundido de la Ley de Propiedad Intelectual, regularizando, aclarando y armonizando las disposiciones legales vigentes sobre la materia).

En referencia a la legislación española Ruth Navarro Costa (NAVARRO COSTA, 2013) establece que "el autor asalariado recibe un sueldo del empresario; la creación del empleado es la contraprestación que ha de pagar por el salario que cobra. Iría en contra del principio de equivalencia de las prestaciones, que además de obtener un sueldo el autor asalariado hiciera suyas las facultades económicas derivadas de su creación: el sueldo ya remunera al autor por sus ideas y creaciones. El empresario realiza unas inversiones, ofrece oportunidades de empleo creativo que no existirían de otra forma, organiza la producción del los materiales de trabajo, la distribución. Es natural que puedan entonces utilizar libremente las obras que han sido desarrolladas gracias a ellos, y que esperen una recompensa razonable por el riesgo que toman. La ley española consigue compaginar estos intereses por medio de la "adquisición automática aunque derivada" del empresario sobre los derechos de explotación económica".

\subsection{La libertad creativa y el poder de dirección.}

El poder de dirección del empleador consiste en la potestad de emitir directivas a los trabajadores mediante órdenes e instrucciones relativas a la forma y modalidad del trabajo, según los fines y necesidades de la empresa contemplados en el artículo 65 de la Ley de Contrato de Trabajo 20744,

“Artículo 65. - Facultad de dirección. Las facultades de dirección que asisten al empleador deberán ejercitarse con carácter funcional, atendiendo a los fines de la empresa, a las exigencias de la producción, sin perjuicio de la preservación y mejora de los derechos personales y patrimoniales del trabajador" (Ley 20.744).

En relación a esto la doctrina ha dicho que debe considerarse que el art. 19 de la Declaración Universal de los Derechos Humanos de 1948, en la que se establece que todo individuo tiene derecho a la libertad de opinión y expresión - libertad de expresión que es género de la cual la libertad de creación es especie - (VIDE, 2014, pág. 4).

El artículo 14 de la Constitución Nacional Argentina consagra el derecho de todo ciudadano de "publicar sus ideas por la prensa sin censura previa", consagrando así el derecho a la libertad de expresión; el cual constituye el género del que la libertad de creación es su especie. Tal como lo señala la jurisprudencia española, citada por Vide (VIDE, 2014, pág. 3) la producción y la creación literaria constituye una "concreción del derecho a expresar libremente pensamientos, ideas y opiniones" (SSTC 153/1985 y 43/2004). El mismo Tribunal señala que "el objetivo principal de este derecho es proteger la libertad del proceso creativo" (STC 51/2008). Consideramos que el derecho a la libertad de creación literaria y artística se vincula directamente con la propiedad intelectual en general y en especial con el derecho de autor, la libertad que se protege es la libertad 
de ser autor, no el derecho del autor sobre la obra. Pero, en el caso del autor asalariado, si consideramos que en el Derecho Laboral el trabajador se ve cercenado en su libertad al momento de contratar en razón de la desigualdad en que se encuentra el trabajador frente a quien detenta el poder económico: ¿existe libertad creativa de quien elabora una obra en relación de dependencia bajo el poder de dirección del empleador? ¿Cómo se compatibiliza este derecho a la libertad creativa del autor asalariado y el poder de dirección del empleador?.

\section{COLOFÓN}

Se hace necesaria la revisión y actualización de la legislación argentina en materia de Derecho de Autor en razón de los cambios tecnológicos y culturales que impactaron, por su trascendencia, en la economía y en él mercado.

Este escenario plantea una serie de problemáticas jurídicas, en torno a la necesidad de regulación adecuada y eficaz, que permita la articulación entre los derechos del creador de la obra y el empresario contratante.

Uno de los inconvenientes que se advierte en torno a la propiedad intelectual, específicamente en lo que refiere al Derecho de Autor, es en relación a los derechos sobre la obra creada mediando una relación contractual antecedente de carácter laboral y la delimitación del derecho de propiedad del autor frente a éstos empresarios productores y comercializadores de bienes y servicios culturales.

En el derecho Argentino no existe una regulación que delimite el ejercicio del derecho por parte del autor asalariado que ha sido contratado para la creación de una obra, simplemente lo reconoce al regular el derecho a la publicación. El autor puede crear su obra espontáneamente sin mediar obligación contractual, o ser contratado para ello y por lo tanto estar ligado a una tercera persona en virtud de éste contrato que puede ser de subordinación laboral. Puede suceder inclusive que se establezcan condiciones determinadas para la creación de la obra, o que el autor pueda realizarla con entera libertad.

En el supuesto de existencia de un contrato laboral entre autor y el empresario contratante cabe cuestionarnos, ¿que alcance tienen los derechos morales y patrimoniales del autor contratado bajo relación de dependencia en relación al empresario contratante?. Consideramos que esta cuestión planteada deberá abordarse a la luz de los principios del Derecho Laboral, de los principios de la Propiedad Intelectual y sus teorías justificatorias, de la jurisprudencia argentina y del Derecho Comparado.

En lo referente al poder de dirección o facultad de dirección del empresario es menester morigerar este derecho a la luz de la capacidad técnica con que cuenta el autor asalariado, el principio protectorio del derecho laboral, el derecho a la libertad creativa, y los derechos derivados del reconocimiento del derecho moral de autor. Pero ¿cómo se resolvería el siguiente supuesto, en caso de que, en uso de su libertad creativa y en defensa de su derecho moral, el autor asalariado se niegue a elaborar una obra encomendada por el empleador, incumpliendo 
con su deber de obediencia y fidelidad, actuando en contra de los propios fines e intereses de la empresa contratante que realiza la inversión y asume los riesgos?. Esta problemática deberá revisarse a la luz de las teorías, la solución dependerá del posicionamiento teórico que se asuma para dirimir la cuestión de éstos derechos en pugna.

\section{REFERENCIAS BIBLIOGRÁFICAS}

Ackerman, M. (2008). Tratado de Derecho del Trabajo Tomo I. Buenos Aires: Rubinzal Culzoni (págs. 324-387).

Ameglio, E. J. (2009). La Subordinación: ¿Sigue siendo la nota que caracteriza al contrato de trabajo?. En A. S. Mario E. ACKERMAN, La Relación de Trabajo (págs. 219-232). Buenos Aires: Rubinzal Culzoni.

Arduino Augusto H.L., AZEVES Ángel Héctor. (2007). "Valuación de la marca en los procesos concursales",. ED.

Arduino, \& Azeves. (2010). "Las Industrias Culturales. Los Derechos Intelectuales. Delimitación de su contenido”,. En M. E. (dir.), Tratado de Derecho Comercial, (pág. 1141). Buenos Aires.: La Ley.

Argentina, Ley de Contrato de Trabajo 20744, Art. 65.

Argentina, Régimen de Propiedad Intelectual $N^{\circ} 11.723$.

CNCiv, Sala B. 22 de 07 de 1963.

Costa, R. N. (20 de 08 de 2013). pendientedemigracion.ucm.es/info/contratos/portada.

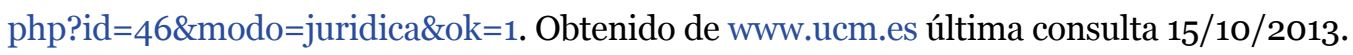

Emery, M. Á. (2009). Propiedad Intelectual. Buenos Aires: Editorial Astrea.

Espín Alba, I. (1994). Contrato de Edición Literaria,. España.: Editorial Comares.

Gomez, E. S. (2000). Los derechos de remuneración de la Propiedad Intelectual. Madrid: Dykinson, S.L.

Nuñez, J. (2001). Alcances y Justificación del derecho moral de autor,. JA, -1-956. 
Ompi., O. M. (15 de 11 de 2013). www.wipo.int. Obtenido de www.wipo.int, última consulta $21 / 11 / 2013$.

Ompi., O. M. (15 de 11 de 2013). www.wipo.int/about-ip/es/. Obtenido de www.wipo.int, $15 / 12 / 2013$.

Perez De Ontiveros Baquero Carmen. (1993.). Derecho de autor: la facultad de decidir la divulgación,. Madrid: Universidad de las Palmas de Canarias Editorial Civitas SA,

Real Decreto Legislativo Español 1/1996.

SSTC 153/1985 y 43/2004.

STC 51/2008.

Supiot, A. (2008). Derecho del Trabajo. Buenos Aires: Heliasta.

Carranza Torres, M. C. (2011). Los principios básicos del derecho de autor. La Ley.

Vide, C. R. (2014). Libertad de creación y derecho de autor. La Ley, 1.

Villalba, C. A. (1990). Derecho de autor y trabajo subordinado. $L L$.

\section{CURRICULUM VITAE}

Augusto H. L. Arduino

Abogado, Ex Vicedecano de la Facultad de Derecho y Ciencias Sociales y Políticas UNNE, actualmente Profesor Titular con dedicación exclusiva en la Cátedra de Derecho Comercial II e Industrial.

\section{hlarduino@yahoo.com.ar}

\section{Silvana S. Ortiz}

Abogada, Especialista en Teoría y Técnica del Proceso Judicial, Doctorando en Derecho de la UNNE, Jefe de Trabajos Prácticos de la Facultad de Derecho y Ciencias Sociales y Políticas UNNE, Becaria de Investigación SGCyT UNNE.

silvansortiz@hotmail.com 